\title{
Giving birth in a Pandemic: Women's Birth Experiences in England during COVID-19
}

Short title: England birth experiences and COVID-19.

Ezra Aydin, $\mathrm{PhD}^{1}$, Kevin A. Glasgow, MPhil ${ }^{2}$, Staci M. Weiss, $\mathrm{PhD}^{1}$, Zahra Khan, BSc ${ }^{1}$, Topun Austin, $\mathrm{MD}^{3.4}$, Mark H. Johnson, $\mathrm{PhD}^{1,6}$, Jane Barlow, DPhil ${ }^{5 *} \&$ Sarah Lloyd-Fox, $\mathrm{PhD}^{1 *}$

${ }^{1}$ Department of Psychology, University of Cambridge, UK.

${ }^{2}$ Department of Education, University of Cambridge, UK.

${ }^{3}$ Neonatal Intensive Care Unit, Cambridge University Hospitals NHS Foundation Trust, Cambridge, UK.

${ }^{4}$ NIHR Cambridge Biomedical Research Centre, Cambridge, UK.

${ }^{5}$ Centre for Evidence-Based Intervention, Department of Social Policy and Intervention, University of Oxford, UK.

${ }^{6}$ Centre for Brain \& Cognitive Development, Birkbeck, University of London, UK

*Joint senior authors

Total word count (without references): 4756

Total table count: 3

Total figure count: 2

Correspondence to: Ezra Aydin, Department of Psychology, University of Cambridge, Downing Street, Cambridge, CB2 3EB, UK. Email: ea420@cam.ac.uk Telephone: +44 (0) 1223465222 


\section{Abstract}

Background: Expectant parents worldwide have experienced changes in the way they give birth as a result of COVID-19, including restrictions relating to access to birthing units and the presence of birthing partners during the birth, and changes to birth plans. This paper reports the experiences of women in England.

Methods: Data were obtained from both closed- and open-ended responses collected as part of the national COVID in Context of Pregnancy, Infancy and Parenting (CoCoPIP) Study online survey $\left(\mathrm{n}=477\right.$ families) between $15^{\text {th }}$ July $2020-29^{\text {th }}$ March 2021 . Frequency data are presented alongside the results of a sentiment analysis; the open-ended data was analysed thematically.

Results: Two-thirds of expectant women reported giving birth via spontaneous vaginal delivery (SVD) $(66.1 \%)$ and a third via caesarean section (CS) $(32.6 \%)$ or 'other' $(1.3 \%)$. Just under half $(49.7 \%)$ of the CS were reported to have been elective/planned, with $47.7 \%$ being emergencies. A third $(37.4 \%)$ of participants reported having no changes to their delivery, with a further $25 \%$ reporting COVID-related changes, and $37.4 \%$ reporting nonCOVID related changes (e.g., medical intervention). Experiences of COVID-related changes included limited birthing options and reduced feelings of control; difficulties accessing painrelief and assistance, and feelings of distress and anxiety. Under half of the respondents reported not knowing whether there could be someone present at the birth (44.8\%), with $2.3 \%$ of respondents reporting no birthing partner being present due to COVID-related restrictions. Parental experiences of communication and advice provided by the hospital prior to delivery were mixed, with significant stress and anxiety being reported in relation to both the fluctuating guidance and lack of certainty regarding the presence of birthing partners at 
the birth. The sentiment analysis revealed that participant experiences of giving birth during the pandemic were predominately negative (46.9\%) particularly in relation to the first national lockdown, with a smaller proportion of positive (33.2\%) and neutral responses $(19.9 \%)$.

Conclusion: Parents reported an overall increase in birthing interventions (e.g., emergency CS), increased uncertainties related to the birth, and poor communication, leading to increased feelings of anxiety and high levels of negative emotions. The implications of these findings are discussed.

Key words: birth experience; COVID-19; thematic analysis; pregnancy; England 
medRxiv preprint doi: https://doi.org/10.1101/2021.07.05.21260022; this version posted July 6, 2021. The copyright holder for this preprint (which was not certified by peer review) is the author/funder, who has granted medRxiv a license to display the preprint in perpetuity. It is made available under a CC-BY-NC 4.0 International license .

\section{Introduction}

2 In January 2020 the first case of COVID-19 in the UK was confirmed, and on the $23^{\text {rd }}$ of

3 March 2020 a national lockdown was announced. For this and two later national lockdowns

4 in England, all non-essential businesses were closed, and people were required to stay at

5 home, being permitted to leave for essential purposes only (e.g., medical workers) (see

$6 \quad$ Figure 1 for timeline and dates of restrictions and guidelines in England).

$8 \quad$ Figure 1: Timeline of restrictions and guidelines* imposed by the government between

$9 \quad$ March 2020-March 2021

10

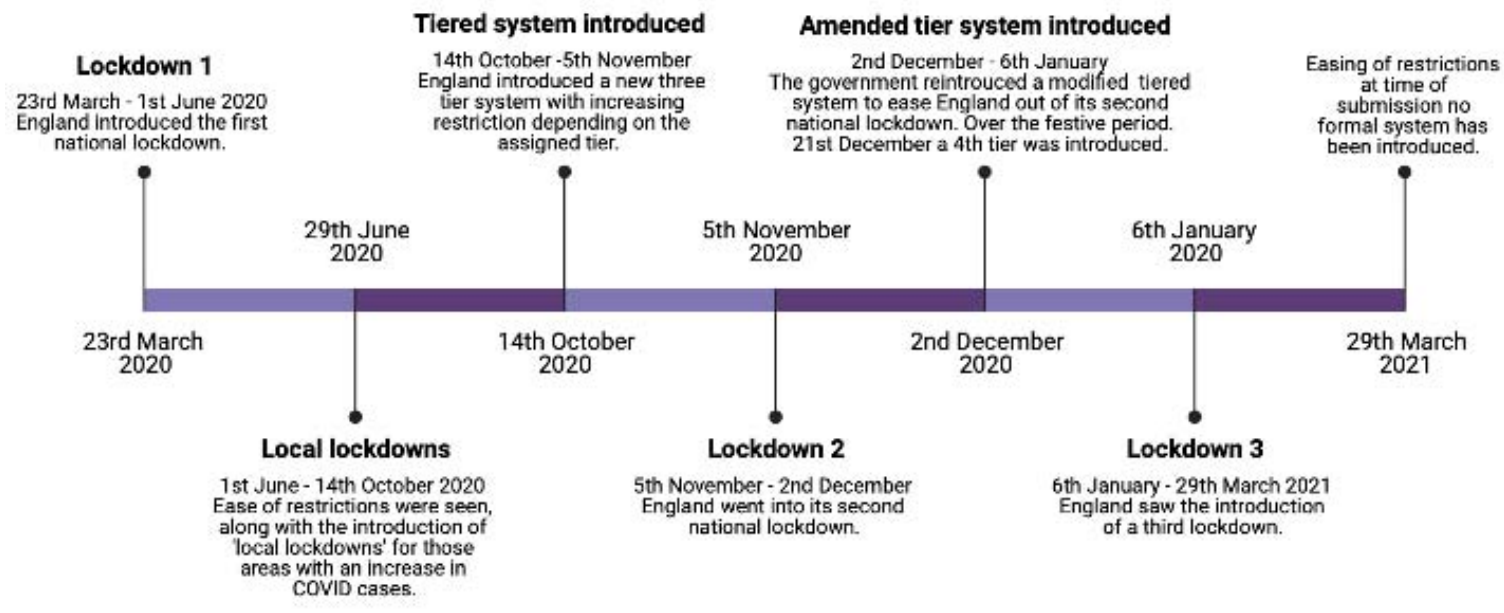

$11 *$ It is important to note that some areas in England may have seen a slight alteration in between national guidance and restrictions rules in his time 12 period.

13

14 Throughout the pandemic, pregnancy and childbirth have been associated with anxiety and

15 uncertainty for many pregnant women and their partners due in part to the changing

16 landscape of the healthcare system and increased demands on healthcare providers. This has

17 resulted in a number of best practices endorsed by the World Health Organising (WHO)

18 being side-lined as evidenced by reports of women giving birth alone (San Francisco: Human

19 Rights in Childbirth, 2020; Walsh et al., 2020), restrictions being imposed on birthing options 
medRxiv preprint doi: https://doi.org/10.1101/2021.07.05.21260022; this version posted July 6, 2021. The copyright holder for this preprint (which was not certified by peer review) is the author/funder, who has granted medRxiv a license to display the preprint in perpetuity. It is made available under a CC-BY-NC 4.0 International license .

20 (e.g., no water births) (Greenfield et al., 2021; Nelson \& Romanis, 2020)), and separation

21 from their baby shortly after birth (San Francisco: Human Rights in Childbirth, 2020).

23 In the UK, government guidelines aimed at curbing the spread of the virus also led to a 24 number of suboptimal conditions for expectant parents giving birth. In March 2020, National

25 Health Service (NHS) trusts began to suspend home birth services and support in response to 26 the COVID-19 outbreak (Davis, 2020). This was the result of a shortage in the number of 27 midwives and maternity support workers (i.e., The Royal College of Midwives (RCM) 28 reported a doubling in the shortage of midwives since the start of the COVID-19 outbreak 29 Royal College of Midwives, 2020; Sherwood, 2020), the diversion of resources to the 30 pandemic, and ambulance shortages. Due to the suspension of NHS-supported home birth 31 services, the RCM reported a surge in expectant women removing themselves from NHS 32 antenatal care and a spike in private midwifery services, with increased numbers of expectant 33 parents avoiding routine and obstetric care in hospitals (Davis, 2020). One study showed that 34 between April and July 2020, one in 20 expectant women were considering giving birth 35 without a doctor or midwife present ('freebirth') in the UK, 3\% higher than recorded in 2019 36 (Greenfield et al., 2021). This qualitative study attributed the increased demand for 37 'freebirths' to wanting to avoid hospitals, fewer choices in terms of birth preferences (e.g., 38 having a birthing partner present), and practical problems (e.g., inability to use public 39 transport) (Greenfield et al., 2021; Nelson \& Romanis, 2020).

41 From the beginning of the pandemic, individual NHS trusts were required to draw up their 42 own guidance with regard to access to maternity services and birth partners, based on 43 government guidelines. Most commonly, the guidance stated that partners were only allowed 44 to be present when the mother was $4 \mathrm{~cm}$ dilated, that they were not allowed to be present at 
45 the start of an induction and were not allowed to join their partners during the pre-operation

46 preparation for a caesarean section (CS); and that they were to leave shortly after the birth

47 (Regan, 2020). A survey of 15,000 new and expectant women conducted by the UK-based

48 charity 'Pregnant then Screwed' between $16-18^{\text {th }}$ July 2020 found that $90 \%$ reported hospital

49 restrictions to have had a negative impact on their mental health, with $97 \%$ reporting these

50 restrictions to have also increased their anxieties related to childbirth. Furthermore, just

51 under a fifth (17.4\%) of respondents reported feeling 'forced' to have a vaginal examination

52 whilst in labour with $82 \%$ feeling this was a requirement if they were to have their birthing

53 partner join them during the delivery.

55 On the $8^{\text {th }}$ September 2020, NHS England issued guidance to individual NHS trusts "to

56 reintroduce access for partners, visitors and other supporters of pregnant women in English

57 maternity services" (Royal College of Obstetricians and Gynaecologists et al., 2020).

58 However, the Guardian reported that only around $23 \%$ of trusts during this period allowed

59 partners to be in attendance for the duration of the labour (Topping \& Duncan, 2020),

60 suggesting this guidance was applied inconsistently across trusts. In December 2020 this

61 guidance was further revised to explicitly allow in-person support for expectant women

62 throughout their maternity journey. This was inclusive of antenatal visits, ultrasound scans,

63 and during the birth (NHS, 2020).

65 The COVID-19 in the Context of Pregnancy, Infant Parenting (CoCoPIP) Study was 66 developed to explore how COVID-19 and the cascade of changes in healthcare, social

67 restrictions and government guidance impacted the lives of families who were expecting a

68 baby or had recently given birth (Aydin, Weiss, et al., 2021). Previously, data collected from

69 the Context of Pregnancy, Infancy and Parenting (CoCoPIP) study was used to qualitatively 
70 explore expectant family's perceptions of their healthcare appointments, health and social

71 support in the UK during the pandemic (Aydin, Glasgow, et al., 2021). The aim of the current

72 analysis was to explore parent's experiences of giving birth during COVID-19, including the

73 ways in which communication and advice provided by hospitals may have influenced these

74 experiences.

\section{Methods}

76 Participants

77 Survey data was taken from the period $15^{\text {th }}$ July $2020-29^{\text {th }}$ March $2021(\mathrm{n}=477$, see Table

781 for demographic and birth information). Recruitment strategies included the distribution of

79 information nationwide to antenatal and postnatal health groups, social media platforms

80 (Twitter, Facebook and Instagram), as well as other child development research groups and

81 networks in the UK. Eligibility criteria for the study included expectant parents past their first

82 trimester, or parents of an infant between the ages of 0-6 months, who were then asked to

83 report on experiences during their recent pregnancy. Women who gave birth prior to the first

84 national lockdown (23 ${ }^{\text {rd }}$ March 2020), were excluded from the final analysis. Additionally,

85 due to the differences in timings with regard to the guidance issued across England, Wales

86 and Scotland, only those families who lived in England at time of birth were included in the

87 final sample. These were identified by the postcode participants provided at time of

88 completing the survey. All participating parents gave informed consent to take part in the

89 CoCoPIP online survey (tinyurl.com/CoCoPIP) (Aydin, Weiss, et al., 2021). Ethics approval

90 for the survey was given by the University of Cambridge, Psychology Research Ethics

91 Committee (PREC) (PRE.2020.077). 
94 Table 1: Participant demographic information

Demographic

Who
Mother
Father
Non-birth Mother
Other partner
Missing
Ethnicity
White
Black
Asian
Mixed/Multiple
Hispanic
Arab
Other
Undisclosed

Gestational age at birth

Very preterm $(<32$ weeks $)$

Moderately preterm ( $32-33$ weeks +6 days)

3

8

21

100

321

24

Post term (>42 weeks)

\section{Delivery method}

Spontaneous vaginal delivery (SVD)

C-section

Elective

Emergency

Other

Procedure

98 The CoCoPIP survey comprises a mixed-methods approach, in which both quantitative and

99 qualitative data was collected. This survey is logic-dependent and adaptive, only showing

100 questions relevant to the parent's current situation (i.e., first trimester/second trimester/infant aged 0-3/3-6 months). For the full survey, response time was $\sim 30$ minutes and respondents 
medRxiv preprint doi: https://doi.org/10.1101/2021.07.05.21260022; this version posted July 6, 2021. The copyright holder for this preprint

(which was not certified by peer review) is the author/funder, who has granted medRxiv a license to display the preprint in perpetuity.

It is made available under a CC-BY-NC 4.0 International license .

103 were asked to complete structured questions about delivery type and whether their partner

104 and/or family were present during the birth (see Table 2 for questions), alongside semi-

105 structured questions focussed on their experience of giving birth during a pandemic (see

106 Table 3 for questions).

107

108 Table 2: Structured questions about partner and/or family access to hospital during birth.

Question

Prior to the birth, were you certain whether partners and/or family could be present for the birth?

Yes

I wasn't sure

No

Missing

Was the partner and/or family present for the birth?

Yes

No

111 Table 3: Semi-structured questions asked to participants regarding their birthing experiences Question

Was the way you delivered your baby as you wanted to in your birth plan, or did it change?

Prior to the birth, were you certain whether partners and/or family could be present for the birth? If you like, let us know how this communication or advice from the hospital made you feel.

\section{Analysis}

115 Descriptive data is presented below in the form of frequencies. Quantitative analysis of the

116 data involved a sentiment analysis. As with previous research (Aydin, Glasgow, et al., 2021),

117 this was conducted manually. Responses to each question (see Table 3) were read and

118 categorised as 'positive', 'negative' or 'neutral' by a single researcher (EA) and a cross check

119 of $10 \%$ of the sentiment labels were conducted by a second researcher (KAG). 
medRxiv preprint doi: https://doi.org/10.1101/2021.07.05.21260022; this version posted July 6, 2021. The copyright holder for this preprint (which was not certified by peer review) is the author/funder, who has granted medRxiv a license to display the preprint in perpetuity. It is made available under a CC-BY-NC 4.0 International license .

121 The qualitative data was imported from Qualtrics® via Redcap® (Harris et al., 2009) into

122 NVivo 12 (QSR International) software. We adopted the same methodology used in previous

123 qualitative research from the CoCoPIP study cohort (Aydin, Glasgow, et al., 2021). The

124 coding trail was double checked by EA. Finally, confirmability was addressed by ensuring a

125 clear presentation of participant responses, and by providing a clear rational for each step

126 involved in the methods and analysis; furthermore, an additional researcher (KAG)

127 conducted a reliability analysis of $25 \%$ of the data to confirm the themes and sub-themes

128 identified. It is important to note that any data reported as occurring 'as a direct result of

129 COVID-19 only' includes answers where the individual explicitly referenced 'COVID',

130 'pandemic' or 'PPE use' in their response to the semi-structured questions asked (see Table $1313)$.

\section{Results}

133 Of the 477 participants who responded to questions regarding their birthing experiences

134 during the pandemic, a third completed the survey during one of the three national lockdowns

$135(39.5 \%, 188)$, around half completed the survey during the period of easing of restrictions

$136(51.5 \%, 245)$ and a small percentage were completed during the introduction of a tiered 137 system $(9 \%, 43)$ (see Figure 1 for timeline).

140 In our sample two-thirds of expectant women gave birth via spontaneous vaginal delivery

141 (SVD) $(66.1 \%, 315)$, a third delivered via CS $(32.6 \%, 155)$, and 'other' $(1.3 \%, 6)$ (see Table

142 1). Of the 155 participants who reported giving birth by CS, just under half $(49.7 \%, 77)$

143 reported having an elective/planned CS, with the remainder $(47.7 \%$; 74$)$ having an 144 emergency CS (4 participants did not report on whether their CS was an elective or 145 emergency procedure). 
147 A large proportion of respondents reported being uncertain about the restrictions relating to 148 birthing partners $(40.2 \%, 191)$, and a fifth reported that they were unaware prior to the birth 149 whether birthing partners would be allowed to be present $(14.9 \%, 71)$ (see Table 2 for

150 questions). At time of birth the majority of participants reported having their partner or a

151 family member present $(96.2 \%, 459)$, whilst a small number reported not being able to have 152 anyone present at the birth $(3.8 \%, 18)$ with $2.3 \%$ of these being due to COVID-19 related 153 restrictions between $23^{\text {rd }}$ March $2020-29^{\text {th }}$ March 2021.

155 The results of the sentiment analysis showed that of the total responses across all questions (n $156=706), 33.2 \%$ expressed positive, $19.9 \%$ neutral and $46.9 \%$ negative sentiments. When 157 observing sentiment in relation to the governmental guidance and restrictions (see Figure 1 158 for timeline) participants responses consistently showed a higher negative sentiment towards 159 their birthing experiences during the first national lockdown (56.9\%), ease of governmental 160 guidance and restrictions, (43\%) and tiered guidance system (42.6\%). Relative to these 161 periods, during the second and third national lockdowns, participants showed an almost equal 162 number of negative (34.2\%) and neutral (36.8\%) sentiments during lockdown 2 and a more 163 positive sentiment $(50 \%)$ with regard to their birthing experiences during lockdown 3 (see 164 Figure 2). 
medRxiv preprint doi: https://doi.org/10.1101/2021.07.05.21260022; this version posted July 6, 2021. The copyright holder for this preprint (which was not certified by peer review) is the author/funder, who has granted medRxiv a license to display the preprint in perpetuity.

It is made available under a CC-BY-NC 4.0 International license .

172 Figure 2: Diagram of sentiment analysis reported by national guidance group at time of 173 birth.

174

175

176

177

178

179

180

181

182

Positive

\section{Lockdown}

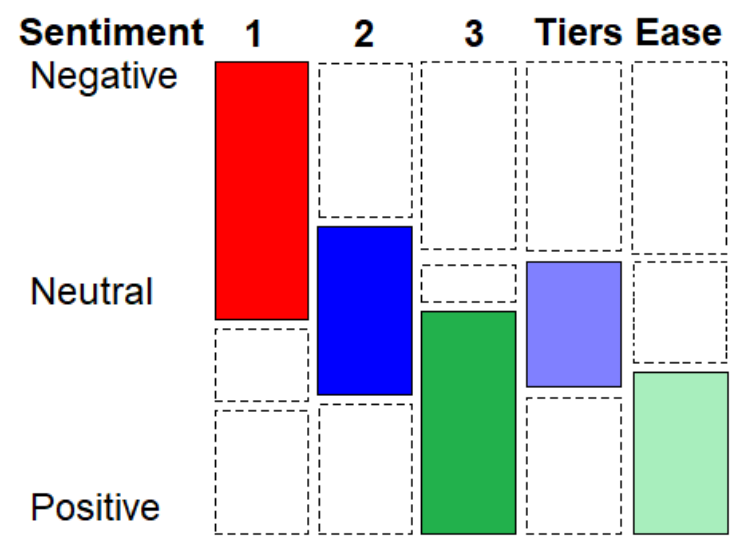

Sentiment Frequency Key

$\square$ 4x more negative than expected

$\square$ 2x more negative than expected

Non-significant from expected

$\square$ 2x more neutral than expected

$4 x$ more neutral than expected

$\square$ 2x more positive than expected

$\square$ 4x more positive than expected

184 Of the 462 respondents who responded to the question 'Was the way you delivered your baby

185 as you wanted to in your birth plan, or did it change? 37.4\% (172) reported no changes to

186 their planned delivery (although it should be noted that some of these responses suggested

187 that no birth plan had been made as a result of the pandemic), 25\% (115) reported changes to

188 the planned delivery due to COVID and 37.4\% (172) reported changes due to other reasons

189 (e.g., changes in birth plan due to fetus being breech). Parents experiences of the COVID-

190 related changes are described below:

\section{No changes to delivery plan}

193 Although many parents across the UK experienced difficulties and hardships whilst giving

194 birth, some respondents to the survey reported their birthing experience going according to

195 their birthing plan, with parents recalling positive experiences in relation to the birth of their

196 child: 
201 'It was the way I wanted to. The birth experience was the most normal thing in the whole pregnancy'

In addition to parents experiencing no changes to their birth plans, some participants described feeling supported and informed at the time of giving birth: '.... My birth plan was followed in that I was able to do and use the things I wanted and the staff knew that I was flexible should I need to be dependent on the situation that arose at the time.'

Another participant referred to additional support offered due to previous birthing trauma: previous birth trauma the year before.' were not being made during national restrictions: lockdown so I didn't have a plan.'

217 While this was experienced well by some women - 'I had no birth plan so it all went how I 218 would of liked it'- other statements suggest that some women felt less clear about the impact 219 of this: slow and long which ended in an emergency caesarean.' 
226 One of the most notable COVID-related changes reported was the suspension of home births 227 and birthing pools:

'Planned home water birth. All home births cancelled. All water births cancelled' too.

This respondent went on to describe the feeling of being rushed and of having no control: access to birth centre or home birth). V[sic] different to what we had planned!'

242 A number of respondents described being alone, and in one case, the cancellation of plans that had been developed to help prevent the reoccurrence of her postnatal depression: partner was only allowed to join me right at the end.' 
251 One respondent reported having trouble accessing the desired pain relief and assistance 252 during her labour: 'It changed I was induced due to potential infection. And was unable to have the desired pain relief and staffing was low, and they didn't arrive in my very quick labour'

These changes and restrictions resulted in some parents feeling considerable distress and anxiety:

\section{Non-COVID related changes to delivery}

262 Whilst changes to delivery can be expected when giving birth (e.g., 'I was induced due to 263 potential infection') women reported feelings of anxiety and distress with regard to these changes due to the lack of support and communication offered by hospitals:

'My birth plan changed as the baby was in a difficult position but as I was the last in my pregnancy group to give birth and 5/7 of them had had a c-section I was very worried I would have to have a c-section. In hospital it felt like it was my only option'

These feelings were further exacerbated as a result of COVID-related restrictions to birthing support: from PTSD from my [eldest's] birth where I was induced therefore it was advised I 
276 Some respondents who described changes to their delivery appeared to adapt well to the 277 changes as a result of feeling supported and informed throughout their journey: 'Things did not go to plan, but I was kept informed, I was consulted on actions taken and my birth plan was considered throughout.'

283 In addition to asking families to share their birthing experiences, we asked parents to reflect on the communication they had received prior to the birth of their baby regarding access to birthing partners during the delivery. We identified three key themes related to responses to this question (see Table 3, Q7, $\mathrm{n}=250$ ): (1) Communication, (2) Impact of fluctuating COVID-related guidance, (3) Anxiety and stress related to changing guidance.

\section{Communication}

The results revealed mixed responses in relation to communication from their hospital prior feelings of anxiety: asked a friend to be a back-up birth partner in case my partner should be barred for such a reason.'

299 Other parents reported having good communication from their hospital and midwives, in 300 particular noting the use of social media platforms: 

very helpful midwife - patient liaison Facebook group’

'My local hospital held a webinar with their midwives discussing what to expect at the birth with the new restrictions so I new [sic] exactly what to expect at [...]. They also answered any other worries or concerns I had on Facebook messenger. It was really helpful and reassuring.'

\section{Impact of fluctuating COVID-related guidance}

310 The constant changes to the guidance and restrictions in relation to giving birth during

311 COVID-19 was a major theme within responses related to communication received from the

312 hospital prior to the birth of their child: 'It changed a lot in the build up to birth - as did restrictions on water birth etc. Was 'Things were changing so quickly at the time midwives weren't 100\% sure'

318 Many parents related the constant and fast changing nature of guidance as causing feelings of 319 distress:

320 'The guidelines were changing almost daily. I felt scared and upset. On top of this I 321 was unsure if anyone would be able to look after my son whilst I gave birth.' 
326 In addition to the changing rules and guidance, parents highlighted differences between the

327 NHS trusts around COVID guidance and birth:

328 'As long as a positive test or symptoms aren't present. It was a concern that they 329 wouldn't let my partner be present as restrictions were tighter than in other local 330 hospitals,

\section{Anxiety and stress related to changing guidance}

333 Many parents reported feelings of anxiety and distress related to not being confident that they

334 would be able to have a birth partner present for the duration of their labour and birth:

'It was awful having no assurance that my partner could attend labour and postlabour. There's not much else to say except it was the \#1 reason for my anxiety in the last few months of pregnancy.'

345 However, the empathy with which this information was conveyed, appeared to have 346 influenced at least one participant's response to this:

347 'At one point my midwife told me that I would have to be alone. This was a shock to 348 me and I had a very emotional response. She was also upset by this. I appreciated 349 that this was out of her control and that there was nothing she could do, I just really $350 \quad$ appreciated her empathic response, I felt less alone in that moment.' 
medRxiv preprint doi: https://doi.org/10.1101/2021.07.05.21260022; this version posted July 6, 2021. The copyright holder for this preprint (which was not certified by peer review) is the author/funder, who has granted medRxiv a license to display the preprint in perpetuity.

It is made available under a CC-BY-NC 4.0 International license .

351

352 Our study sought to identify the impact of giving birth amidst the changes in public health

353 guidance that were instigated during the COVID-19 pandemic. The CoCoPIP survey

354 provided new mothers with the opportunity to describe their experiences in their own words

355 within the first 6 months following birth. Analyses compared expressed sentiment (i.e.,

356 positive, negative and neutral) across lockdown conditions and coded the themes expressed

357 by parents' open-ended responses, as well as describing the type of delivery, the presence of

358 birthing partners, and changes in birth plan reported by our sample. To date, our study

359 provides the largest sentiment analysis of birth experiences in the UK (Ayers, 2007).

361 Our results show that $32.6 \%$ of participants reported having a CS, of which $47.7 \%$ were elective. This represents a significant increase relative to pre-pandemic levels in which around one-quarter of deliveries were typically CS and one-third elective (NHS, 2019). At the start of the pandemic, there were reports that maternal requests for caesarean sections (MRCS) were under a blanket restriction (Romanis \& Nelson, 2020). However this subsequently changed, with reports of expectant women in England and Wales opting to have

367 a CS to ensure the presence of birthing partners at birth (Betteley, 2020). This was in 368 response stories of partners being unable to reach the hospital in time for the 'active labour' 369 portion of their baby's delivery (Betteley, 2020). Whilst the current study did not explicitly

370 ask whether respondents elected to have a CS, our results indicated a higher-than-average 371 rate of elective CS, despite the governmental guidance and restrictions in place, suggesting 372 the presence of a partner might have been a potential motivation for this plan.

374 The results also show that just under half the total sample reported that they were unsure 375 whether their birthing partner would be able to attend the delivery (40.2\%), demonstrating 
376 uncertainty around access to birth partners throughout the year of the pandemic. When asked

377 to elaborate on how this communication (or lack of) from the hospital made expectant

378 mothers feel (see Q7), a large proportion of individuals reported heightened levels of anxiety

379 and distress. While NHS England has stated that guidance has been clear throughout the

380 pandemic allowing partners to be present for childbirth, this was not always the case

381 (Summers, 2020). For example, the Guardian reported in September 2020 that "three-

382 quarters of NHS trusts are not allowing birth parents to support mothers" (Topping \&

383 Duncan, 2020). Within the NHS, each trust was able to issue their own policy, in particular

384 those regarding access to birthing partners (Summers, 2020), leading to inconsistency and

385 confusion across regions and among different expectant families. Our data highlights the way

386 in which the changes in the rules and guidance surrounding birthing preferences and birth

387 partners, not only nationally but between NHS trusts, created confusion and anxiety amongst

388 families. This lack of clear guidance appears to have exacerbated existing feelings of stress

389 and anxiety in women throughout their pregnancy (Aydin, Glasgow, et al., 2021), not only

390 during childbirth.

391

392 The results of the sentiment analysis suggest that the fluctuations in guidance and the

393 evolving crisis in terms of the provision of services to pregnant women, led to higher-than-

394 typical (9.3\%) reports of negative birth experiences (Rijnders et al., 2008; Smarandache et

395 al., 2016). In our sample, the uncertainty that characterised the initial phase of lockdown

396 seemed to exacerbate the frequency of negative experiences (Smarandache, Kim, Bohr, \&

397 Tamim, 2016).

399 Results from our thematic analysis support those of a survey conducted by Mumsnet and

400 Birthrights between December 2019 - September 2020, which found that many women 
401 reported that their decisions with regard to childbirth (e.g., water birth, delayed clamping)

402 were not respected with many reporting their choice was either not considered or disregarded

403 (Mumsnet \& Birthrights, 2020). These changes, in addition to uncertainties with regard to

404 access for the birthing partner throughout the pandemic were described as having led to

405 heightened levels of anxiety and a negative childbirth experience.

407 The findings also suggest, however, that whilst changes to the birth were experienced by a 408 large proportion of our sample, clear communication and support appeared to mitigate these 409 negative childbirth experiences. These findings are consistent with the wider recognition that

410 women's feelings and ability to exert choice and control during the birth, are more important 411 in terms of long-term wellbeing, than the objective facts of the birth (Cook \& Loomis, 2012).

412 It is also now recognised that post-traumatic stress disorder (PTSD) can occur following 413 childbirth and has been found to be influenced by a number of significant factors, including 414 some that were identified by the current study (i.e. negative aspects in staff-mother contact, 415 feelings of loss of control over the situation, and lack of partner support) (Olde et al., 2006).

416 While we do not currently have data with regard to the incidence of PTSD following 417 childbirth during the pandemic, this study found that when families were provided with 418 support and the ability to control the decision-making about the overall birth (e.g., birth plan 419 was followed or communication facilitated by midwives) families concurrently reported a 420 more positive experience with reduced levels of anxiety and stress. Overwhelmingly, 421 however, women reported negative birthing experiences when discussing (i) restrictions in 422 terms of birthing method (i.e., no access to birthing pool or home births), (ii) no offer of 423 support and communication by medical staff and/or (iii) dismissals of their decision with 424 regard to how they wished to give birth. 
medRxiv preprint doi: https://doi.org/10.1101/2021.07.05.21260022; this version posted July 6, 2021. The copyright holder for this preprint (which was not certified by peer review) is the author/funder, who has granted medRxiv a license to display the preprint in perpetuity.

It is made available under a CC-BY-NC 4.0 International license .

\section{Limitations}

427 As data were collected between July 2020 - March 2021, participants experiences reflect a

428 period of fluctuating COVID-related government and healthcare restrictions, from the most

429 severe national lockdown measures to a combination of severe to mild national/local

430 restrictions. Due to the rapidly evolving nature of the governmental guidance related to the

431 pandemic and regional variations in between national lockdowns it, was not possible to

432 collect equal sample sizes at each timepoint. Furthermore, as a result of the fact that this

433 study was conducted as a voluntary online survey, we cannot confirm independently that all

434 responses were by expectant parents or exclude bias in respondents with either positive or

435 negative experience of giving birth. Whilst we advertised this study nationally and

436 specifically worked with national childbirth trusts (NCTs) with an emphasis on areas of low

437 socio-economic status (SES), the majority of participants were white; therefore, the results

438 cannot be generalised to a more ethnically diverse population. Furthermore, while our sample

439 was fairly representative of the UK's population, there was an underrepresentation of Asian

440 and South Asian parents. This study is part of an ongoing longitudinal study observing the

441 impact of COVID-19 on pregnancy, infant development and parental mental health and we

442 hope we increase the diversity of our sample as recruitment continues. Another limitation is

443 that, of the two questions posed, not every participant gave a response to each one. Finally,

444 from a qualitative perspective, due to the online survey nature of the project, it was not

445 possible to probe by means of interviews, which would for example have helped us further

446 elucidate the links between whether the existence of detailed guidance given by the trust

447 influenced the birth accounts and contributed to the specific reasoning behind the change in 448 birth plan. 
medRxiv preprint doi: https://doi.org/10.1101/2021.07.05.21260022; this version posted July 6, 2021. The copyright holder for this preprint (which was not certified by peer review) is the author/funder, who has granted medRxiv a license to display the preprint in perpetuity.

It is made available under a CC-BY-NC 4.0 International license .

Implications for practice and research

451 The mitigation measures implemented by the government and the NHS throughout the

452 COVID-19 pandemic have had a significant secondary impact on expectant women and

453 families. Going forward, these findings show the need for clear and consistent guidance to be

454 in place for expectant women giving birth during subsequent lockdowns and any future

455 public health crises. This should include allowances for choice of delivery methods as well as

456 the availability of consistent support for the duration of the labour and birth.

457

458 Further research is needed to explore the impact of variation in birth experiences, both on 459 maternal mental health in the postpartum period (Simpson \& Catling, 2016), on maternal460 infant attachment (Anderson \& Cacola, 2017), and on subsequent maternal health and child 461 development (Hernández-Martínez et al., 2020). Maternal recovery and bonding with their 462 infants are particularly salient in light of the relative social isolation experienced by families 463 during the pandemic.

465 Conclusions

466 Changes to birth experiences and offered support - in response to governmental guidance 467 with regard to mitigating the spread of the virus and the increased burden on the healthcare 468 system - has had an adverse effect on the experiences of many pregnant women in England.

469 These findings reinforce the importance of the role of choice and control in women's 470 childbirth experience. In addition, the findings demonstrate the need to ensure consistent 471 guidance and support to better address the unique health care needs of each pregnant woman 472 in any future lockdowns, as well as the need to observe the potential long-term impact on 473 their offspring. 


\section{List of abbreviations}

476 NHS: National Health Service

477 RCM: Royal College of Midwives

478 CS: Caesarean section

479 PTSD: Post-traumatic stress disorder

480

481

482

483

484

485

486

487

488 Declarations

489 Ethics approval and consent to participate: Ethics approval for the survey was given by

490 the University of Cambridge, Psychology Research Ethics Committee (PREC)

491 (PRE.2020.077).

492

493 Consent for publication: Not applicable.

495 Availability of data and materials: Qualitative data generated and analysed during the

496 study will not be made publicly available due to ethical and privacy restrictions, however

497 researchers can submit a research proposal to the Data Sharing Management Committee to request access and collaboration. 
medRxiv preprint doi: https://doi.org/10.1101/2021.07.05.21260022; this version posted July 6, 2021. The copyright holder for this preprint (which was not certified by peer review) is the author/funder, who has granted medRxiv a license to display the preprint in perpetuity. It is made available under a CC-BY-NC 4.0 International license .

500 Competing interests: The authors have no potential conflicts of interest to disclose.

501

502 Funding source: This research was funded by a Medical Research Council Programme

503 Grant MR/T003057/1 to MJ, and a UKRI Future Leaders fellowship (grant MR/S018425/1)

504 to SLF. The views expressed are those of the authors and not necessarily those of the MRC or

505 the UKRI. T.A. is supported by the NIHR Cambridge Biomedical Research Centre (BRC).

506 The NIHR Cambridge Biomedical Research Centre (BRC) is a partnership between

507 Cambridge University Hospitals NHS Foundation Trust and the University of Cambridge,

508 funded by the National Institute for Health Research (NIHR), TA is also supported by the

509 NIHR Brain Injury MedTech Co-operative. The views expressed are those of the author(s)

510 and not necessarily those of the NIHR or the Department of Health and Social Care.

511

512 Acknowledgements: We are extremely grateful to all those families who gave their time to

513 participate and to Esther Adememo and Maddie Walton who worked on the CoCoPIP study

514 during their undergraduate studies at Cambridge.

516 Author statement: Ezra Aydin: Conceptualization, Methodology, Investigation, Data

517 Curation, Formal Analysis, Validation, Writing - Original Draft. Staci M. Weiss:

518 Conceptualization, Methodology, Formal Analysis, Visualizing, Writing - Review \& Editing.

519 Zahra Khan: Investigation, Data Curation, Validation. Kevin A. Glasgow: Investigation,

520 Data Curation, Formal Analysis, Writing - Review \& Editing. Topun Austin: Methodology,

521 Supervision, Writing - Review \& Editing. Mark Johnson: Supervision, Funding acquisition,

522 Writing - Review \& Editing. Jane Barlow: Supervision, Writing - Review \& Editing. Sarah

523 Lloyd-Fox: Conceptualization, Methodology, Supervision, Funding acquisition, Writing -

\section{Review \& Editing}




\section{References}

538 Anderson, C., \& Cacola, P. (2017). Implications of Preterm Birth for Maternal Mental Health and Infant Development. MCN. The American Journal of Maternal Child Nursing, 42(2), 108-114. https://doi.org/10.1097/NMC.0000000000000311

541 Aydin, E., Glasgow, K. A., Weiss, S., Austin, T., Johnson, M., Barlow, J., \& Lloyd-Fox, S. (2021). Expectant parents' perceptions of healthcare and support during COVID-19 in the UK: A thematic analysis. [Preprint]. Public and Global Health. https://doi.org/10.1101/2021.04.14.21255490

545 Aydin, E., Weiss, S. M., Glasgow, K. A., Barlow, J., Austin, T., Johnson, M. H., \& Lloyd-

546 Fox, S. (2021). The COVID in the Context of Pregnancy, Infancy and Parenting

547 (CoCoPIP) Study: Protocol for a longitudinal study of parental mental health, social

548 interactions, physical growth, and cognitive development of infants during the

549 pandemic. [Preprint]. Health Policy. https://doi.org/10.1101/2021.05.22.21257649 
medRxiv preprint doi: https://doi.org/10.1101/2021.07.05.21260022; this version posted July 6, 2021. The copyright holder for this preprint (which was not certified by peer review) is the author/funder, who has granted medRxiv a license to display the preprint in perpetuity. It is made available under a CC-BY-NC 4.0 International license.

550 Ayers, S. (2007). Thoughts and Emotions During Traumatic Birth: A Qualitative Study. Birth, 34(3), 253-263. https://doi.org/10.1111/j.1523-536X.2007.00178.x

Betteley, C. (2020, September 26). Covid: Pregnant women 'opt for C-section' to ensure partners at birth. https://www.bbc.co.uk/news/uk-wales-54263166

Cook, K., \& Loomis, C. (2012). The Impact of Choice and Control on Women's Childbirth Experiences. The Journal of Perinatal Education, 21(3), 158-168. https://doi.org/10.1891/1058-1243.21.3.158

Davis, N. (2020, March 27). NHS trusts begin suspending home births due to coronavirus. Place: Considering "Freebirth" During Covid-19. Frontiers in Global Women's Health, 2, 603744. https://doi.org/10.3389/fgwh.2021.603744

561 Harris, P. A., Taylor, R., Thielke, R., Payne, J., Gonzalez, N., \& Conde, J. G. (2009). Research electronic data capture (REDCap)_A metadata-driven methodology and https://doi.org/10.1016/j.wombi.2019.03.008

Mayopoulos, G. A., Ein-Dor, T., Dishy, G. A., Nandru, R., Chan, S. J., Hanley, L. E., Kaimal, A. J., \& Dekel, S. (2021). COVID-19 is associated with traumatic childbirth and subsequent mother-infant bonding problems. Journal of Affective Disorders, 282, 122-125. https://doi.org/10.1016/j.jad.2020.12.101 
medRxiv preprint doi: https://doi.org/10.1101/2021.07.05.21260022; this version posted July 6, 2021. The copyright holder for this preprint (which was not certified by peer review) is the author/funder, who has granted medRxiv a license to display the preprint in perpetuity. It is made available under a CC-BY-NC 4.0 International license.

574 Mumsnet \& Birthrights. (2020). A quarter of mothers say their decisions were not respected 575 when giving birth. https://www.birthrights.org.uk/news/press/

576 Nelson, A., \& Romanis, E. C. (2020, April 2). Home-Birthing and Free-Birthing in the era of COVID-19. BMJ Sexual and Reproductive Health.

578 NHS. (2019). Maternity Services Monthly Statistics June 2019, experimental statistics.

579 https://digital.nhs.uk/data-and-information/publications/statistical/maternity-services-

580 monthly-statistics/june-2019

581 NHS. (2020). Supporting Pregnant women using maternity service during the coronavirus $582 \quad$ pandemic: Actions for NHS providers.

583 Olde, E., Vanderhart, O., Kleber, R., \& Vanson, M. (2006). Posttraumatic stress following $584 \quad$ childbirth: A review. Clinical Psychology Review, 26(1), 1-16.

$585 \quad$ https://doi.org/10.1016/j.cpr.2005.07.002

586 Regan, A. (2020, September 26). Coronavirus: The fight to get partners back into maternity $587 \quad$ wards. https://www.bbc.co.uk/news/uk-england-54209927

588 Rijnders, M., Baston, H., Schönbeck, Y., van der Pal, K., Prins, M., Green, J., \& Buitendijk, S. (2008). Perinatal factors related to negative or positive recall of birth experience in women 3 years postpartum in the Netherlands. Birth (Berkeley, Calif.), 35(2), 107-

592 Romanis, E. C., \& Nelson, A. (2020). Maternal request caesareans and COVID-19: The virus does not diminish the importance of choice in childbirth. Journal of Medical Ethics, 46(11), 726-731. https://doi.org/10.1136/medethics-2020-106526

596 pregnant women. https://www.rcm.org.uk/media-releases/2020/march/rcm-plea-help597 us-deliver-safe-care-for-pregnant-women/ 
598 Royal College of Obstetricians and Gynaecologists, Royal College of Midwives, Society and reintroduce access for partners, visitors and other supporters of pregnant women in English maternity services.

604 San Francisco: Human Rights in Childbirth. (2020). Human Rights Violations in Pregnancy, 605 Birth and Postpartum During the COVID-19 Pandemic.

606 Sherwood, H. (2020, March 29). Midwife shortage doubles as NHS staff diverted to tend Covid-19 patients.

608 Simpson, M., \& Catling, C. (2016). Understanding psychological traumatic birth experiences: A literature review. Women and Birth: Journal of the Australian College of Midwives,

611 Smarandache, A., Kim, T. H. M., Bohr, Y., \& Tamim, H. (2016). Predictors of a negative 612 labour and birth experience based on a national survey of Canadian women. BMC 613 Pregnancy and Childbirth, 16(1), 114. https://doi.org/10.1186/s12884-016-0903-2

614 Summers, H. (2020, December 5). 'Women feel they have no option but to give birth alone':

$615 \quad$ The rise of freebirthing.

616 https://www.theguardian.com/lifeandstyle/2020/dec/05/women-give-birth-alone-the-

$617 \quad$ rise-of-freebirthing

618 Topping, A., \& Duncan, P. (2020, September 25). Only 23\% of NHS trusts letting birth 619 partners stay for whole of labour.

620 https://www.theguardian.com/society/2020/sep/25/only-23-of-nhs-trusts-letting-birth621 partners-stay-for-whole-of-labour-covid 
medRxiv preprint doi: https://doi.org/10.1101/2021.07.05.21260022; this version posted July 6, 2021. The copyright holder for this preprint (which was not certified by peer review) is the author/funder, who has granted medRxiv a license to display the preprint in perpetuity. It is made available under a CC-BY-NC 4.0 International license .

622 Walsh, S., Simmons-Jones, F., \& Best, R. (2020). Care during covid-19: Partner attendance

623 at maternity services. BMJ, m3973. https://doi.org/10.1136/bmj.m3973

624

625

626 